\title{
Programmed Intermittent Boluses of Ropivacaine may Provide Superior Analgesia Compared with Continuous Infusion via Paravertebral Catheters following Thoracic Surgery
}

\section{Bridget Bishop}

Austin Hospital

Luke Willshire

Austin Hospital

Matthew Kilpin ( $\square$ matthew.kilpin@gmail.com )

Austin Hospital https://orcid.org/0000-0003-4035-7867

Chong Tan

Austin Hospital

Laurence Weinberg

Austin Hospital

\section{Brett Pearce}

Austin Hospital

\section{Research Article}

Keywords: Local anaesthetic, factors influencing onset, Anaesthetic absorption, regional anesthetic techniques

Posted Date: January 3rd, 2019

DOI: https://doi.org/10.21203/rs.2.170/v1

License: (c) (1) This work is licensed under a Creative Commons Attribution 4.0 International License. Read Full License 


\section{Abstract}

Background: Extrapleural paravertebral local anaesthetic catheters are an effective method of postoperative analgesia. We investigated if delivery of ropivacaine via programmed intermittent boluses provided superior analgesia to continuous infusion alone in patients after thoracic surgery.

Methods: A single-centre, retrospective study of 84 adult patients who received an extrapleural paravertebral catheter following thoracic surgery was performed. Patients were stratified into two groups based on the percentage of the total daily ropivacaine dose delivered as a bolus: continuous infusion (< $10 \% ; n=29)$ and programmed intermittent bolus $(>10 \% ; n=55)$. Outcomes included opioid consumption, pain scores, and ketamine use.

Results: Both groups were comparable. Mean (standard deviation) oral morphine equivalent daily dose consumption on day one, the primary outcome, was $173.4 \mathrm{mg}(139.7 \mathrm{mg})$ for the continuous infusion group compared to $129.2 \mathrm{mg}(100.4 \mathrm{mg})$ for the programmed intermittent bolus group, $p=0.10$. On day two, the mean (standard deviation) was $149.8 \mathrm{mg}(130.2 \mathrm{mg})$ and $102.5 \mathrm{mg}(94.6 \mathrm{mg})$ respectively, $p=$ 0.08 . On day three this reached significance with $178.1 \mathrm{mg}(150.6 \mathrm{mg})$ for the continuous infusion group compared to $80.1 \mathrm{mg}(74.6 \mathrm{mg})$ for the programmed intermittent bolus group, $p=0.001$. There was also a reduction in the number of patients requiring ketamine in the programmed intermittent bolus group on day two $(p=0.02)$ and day three $(p=0.04)$. There was no difference in pain scores.

Conclusion: In patients receiving extrapleural paravertebral catheters after thoracic surgery, the delivery of ropivacaine via programmed intermittent boluses may provide superior analgesia compared to continuous infusion alone.

\section{Background}

The management of pain after thoracotomy and video-assisted thoracoscopic surgery (VATS) is important given that these procedures are considered to be among the most painful of operations [1-3]. Pain after thoracic surgery can lead to significant morbidity if not adequately controlled, including atelectasis, intra-pulmonary shunting, hypoxaemia, infection, delayed mobilisation, longer hospital stay, and chronic pain [1-5]. Therefore, optimising analgesia is important for patient outcomes. It is widely accepted that surgically sited extrapleural paravertebral local anaesthetic (LA) catheters are a safe and effective method of analgesia for patients following thoracic surgery, including thoracotomy and VATS [6-12].

With the increasing availability of infusion pumps with the technology to administer programmed intermittent boluses (PIB), there has been growing interest in determining if there is any benefit from this technique. Whilst superior analgesia with programmed intermittent boluses, particularly with catheters in the epidural [13-16], femoral [17], adductor canal [18] and popliteal spaces [19,20], has been 
demonstrated, other authors have shown no improvement with automated boluses [21-28]. This may reflect variations in anatomical structures or differences in protocols, in particular, LA bolus volume and frequency.

To date, two clinical trials have compared the analgesic efficacy of intermittent boluses of LA to a continuous infusion in patients receiving a paravertebral catheter after thoracic surgery [21,22]. In both trials, the catheters were located in the paravertebral space, which is continuous with the extrapleural space. Importantly there are no anatomical boundaries to prevent spread of LA between the paravertebral and extrapleural spaces [1,29]. Fibla et al (2015) [21] showed no difference in those receiving PIB compared to continuous infusion, while Català et al (1996) [22], in a small trial, demonstrated increased pain in the PIB group relative to the continuous infusion group. Of particular importance, in both of these studies, the boluses were administered only every six hours without a background infusion.

Given that other aforementioned studies have demonstrated improvement in peripheral nerve blockade with a bolus technique using a higher volume and frequency of boluses, we sought to investigate whether PIB administration of LA on a background infusion provided superior analgesia to continuous infusion alone in patients receiving an extrapleural paravertebral catheter after thoracic surgery.

\section{Methods}

\section{Patient population}

Following institutional ethics review (LNR/17/Austin/466), we conducted a retrospective, single-centred, observational study to assess adult patients who received LA via a surgically sited extrapleural paravertebral catheter following VATS or thoracotomy at the Austin Hospital from September 2016 to November 2017. The Austin Hospital is a tertiary level university teaching hospital in Melbourne, Australia, with a dedicated high-volume thoracic surgical service.

The extrapleural paravertebral catheters were all placed intraoperatively under direct vision by the surgeon and were loaded with a bolus of $30 \mathrm{~mL} 0.5 \%$ ropivacaine. The post-operative delivery of LA was by PIB with a background continuous infusion, or continuous infusion alone, at the discretion of the treating clinician. All patients received post-operative care from the thoracic surgical unit and a dedicated acute pain service.

Patients were included for analysis if they underwent thoracotomy or VATS, and had a surgically sited extrapleural paravertebral catheter for delivery of LA. Patients were excluded if they had thoracotomy or VATS for minimally invasive cardiac surgery, oesophagectomy, or any combined abdominal and thoracic procedure. Patients were also excluded if they received intrathecal morphine or were opioid-tolerant preoperatively, defined as greater than $60 \mathrm{mg}$ of Oral Morphine Equivalent Daily Doses (OMEDDs). In addition, patients were excluded if they had already been included earlier in the study period, or if they underwent multiple procedures during the one hospital admission. All extrapleural paravertebral catheters remained in situ until intercostal drain removal. 


\section{Data collection}

Data were collected from our institution's scanned medical record. Baseline documentation including age, sex, body mass index (BMI), procedure, pre-operative opiate consumption, and administration of other analgesics, was recorded.

Post-operative opiate use via oral and parenteral administration, including patient-controlled analgesia, was recorded and converted to OMEDDs to allow comparison between patients and over time [30-32]. Conversion ratios to OMEDDs were taken from the Australia and New Zealand College of Anaesthetists Faculty of Pain Medicine Opioid Calculator App v1.0 [33]. Post-operative pain scores are routinely documented on the observation chart as per the 11-point Numerical Rating Scale (NRS), with patients asked to provide a verbal rating on the severity of their pain from zero to ten, where zero is no pain and ten is the worst possible pain [34]. The maximum and minimum pain scores in a 24-hour period, regardless of it was at rest or on movement, were recorded. Details regarding the LA catheter regimen, including infusion rates, programmed bolus volume and frequency, and rescue boluses were recorded, and from this the total daily ropivacaine dose was calculated. Adverse outcomes, including the activation of the intensive care unit's medical emergency team (MET), and the resuscitation team via a code blue, were documented. The duration of hospital admission was also recorded.

\section{Key outcomes}

On each post-operative day, i.e., day zero to three inclusive, patients were independently stratified into two groups based on the percentage of their total daily ropivacaine dose they received as boluses. The control group, who received ropivacaine predominantly via continuous infusion (Cl group), had less than $10 \%$ of their total daily ropivacaine dose as a bolus. The cut-off of $10 \%$ accounts for the administration of rescue boluses amongst the continuous infusion group. The programmed intermittent bolus group (PIB group) had greater than or equal to $10 \%$ of their total daily ropivacaine dose as a bolus, i.e., they received LA via a PIB regimen with a background continuous infusion, rather than PIB alone.

In order to determine if the amount of LA given as boluses influenced the results, we subdivided the PIB group into low dose PIB (PIB-L group) with 10-25\% of their total daily ropivacaine dose received as boluses, and high dose PIB (PIB-H group) with greater than or equal to $25 \%$.

Our primary outcome was a univariate comparison of cumulative OMEDD consumption day one postthoracic surgery. Day one was considered to start at 8:00am the morning after surgery. Secondary outcomes included univariate comparison of OMEDD consumption on days two and three postoperatively, daily pain scores via the NRS, daily ketamine use, daily total ropivacaine dose, daily requirement for rescue boluses of ropivacaine, and subgroup analysis of the PIB-L and PIB-H groups compared to the $\mathrm{Cl}$ group. We also conducted multivariate linear regression analysis to examine for confounding effects of other independent variables on the univariate outcomes of interest. 
Continuous data was tested for normality using the D'Agnostino-Pearson omnibus test. For the primary end point between groups, comparisons for continuous data were performed with the use of Student's ttest. All tests were considered two-tailed and we considered a p-value $<0.05$ to indicate statistical significance. Values were reported as mean and standard deviation (SD). The use of ketamine was dichotomised to administered or not administered on each particular day, and analysed using Fisher's exact test. We performed multivariate linear regression within the recommended limits of one covariate for every ten samples. We reported Standardised Coefficients to compare the relative effects of different covariates on the outcome of interest. A power calculation based on a previous audit, (mean OMEDDs $167 \mathrm{mg}$, SD $80 \mathrm{mg}$ ) with an alpha of 0.05 , beta of 0.8 , and an expected decrease of $30 \%$, yielded a sample size of 90 patients. Allowing for poor data and exclusions we aimed to study 100 patients.

Data analyses were performed using GraphPad Prism version 6.0 (GraphPad Software, La Jolla California) and SPSS V21 for Mac (IBM, New York, USA).

\section{Results}

The acute pain service patient database was used to capture patients. A total of 101 patients consecutively received an extrapleural paravertebral catheter after thoracic surgery during the assessment period. Overall, 17 patients were excluded, comprising seven patients who were opioid tolerant pre-operatively, three patients who had an oesophagectomy, one patient who underwent multiple procedures, and six patients who had insufficient data. Patients with insufficient data often had the extrapleural paravertebral catheter removed prior to the end of post-operative day one. Therefore, 84 patients were included for analysis (Figure 1).

Patient drop-out was observed as the extrapleural paravertebral catheters were sometimes removed prior to post-operative day three, with 84 patients analysed on post-operative day one, 78 on day two, and 61 on day three, as shown in Table 1. Treatment group crossover was also observed, with six patients moving from the $\mathrm{Cl}$ group to the PIB group on post-operative day one due to regimen change by the treating clinician. Additionally, two patients moved from the PIB group to the $\mathrm{Cl}$ group.

On univariate analysis, there was no difference between the $\mathrm{Cl}$ and PIB groups in baseline characteristics, including age, sex, BMI, pre-operative OMEDD consumption, type of thoracic surgery, primary opiate administered post-operatively, and total daily ropivacaine dose (Table 2 ). All patients received $0.2 \%$ ropivacaine via their extrapleural paravertebral catheters, and no single patient received a higher daily ropivacaine dose than the manufacturer's recommendation of 770mg per day [35].

On post-operative day one, there were 29 patients (34.5\%) in the $\mathrm{Cl}$ group, and 55 patients $(65.5 \%)$ in the PIB group. Of those in the PIB group, 34 (61.8\%) were in the PIB-L group and 21 (38.2\%) were in the PIB-H group. 
The PIB group had lower mean OMEDD consumption on each day post-thoracic surgery compared to controls, which was statistically significant on post-operative day three. Mean (SD) OMEDD consumption on day one, the primary outcome, was $173.4 \mathrm{mg}(139.7 \mathrm{mg})$ for the $\mathrm{Cl}$ group compared to $129.2 \mathrm{mg}$ (100.4mg) for the PIB group, which is a mean difference of $44.1 \mathrm{mg}(95 \% \mathrm{Cl}:-8.5$ to 96.9$), p=0.10$.

Mean (SD) OMEDD consumption on day two was $149.8 \mathrm{mg}(130.2 \mathrm{mg})$ for the $\mathrm{Cl}$ group compared to $102.5 \mathrm{mg}(94.6 \mathrm{mg})$ for the PIB group, i.e., a mean difference of $47.3 \mathrm{mg}$ ( $95 \% \mathrm{Cl}:-5.2$ to 99.7$), p=0.08$. Mean (SD) OMEDD consumption on day three was $178.1 \mathrm{mg}(150.6 \mathrm{mg})$ for the $\mathrm{Cl}$ group compared to $80.1 \mathrm{mg}$ (74.6mg) for the PIB group, i.e., a mean difference of $98.1 \mathrm{mg}(95 \% \mathrm{Cl}: 39.7$ to 156), $p=0.001$. A comparison of post-operative OMEDD consumption between the $\mathrm{Cl}$ and PIB groups is presented in Figure 2 .

There was a reduction in the number of patients requiring ketamine infusions in the PIB group compared with the $\mathrm{Cl}$ group on each post-operative day, which was statistically significant on day two $(p=0.02)$ and day three $(p=0.04)$. The PIB group also required fewer rescue boluses on post-operative day three $(p=0.01)$ (Table 3$)$.

There was no difference in maximum numerical rating scale pain scores on each post-operative day (Figure 3). The mean (SD) maximum pain score on day one was 6.8 (1.9) for the $\mathrm{Cl}$ group and 6.3 (2.3) for the PIB group $(p=0.31)$. On day two, the mean (SD) maximum pain score was $6.3(1.8)$ and $5.4(2.1)$ $(p=0.11)$, while on day three it was $6.2(2.7)$ and $5.4(2.3)(p=0.25)$ for the $\mathrm{Cl}$ and PIB groups respectively.

\section{Subgroup Analysis}

Subgroup analysis demonstrated a consistently greater effect for the PIB-H group. The PIB-H group had a greater reduction in OMEDD use on all days when compared with the $\mathrm{Cl}$ group, which was statistically significant on days two and three. On day one, mean (SD) OMEDD consumption was $127.3 \mathrm{mg}$ (99.4mg) for the PIB-L group and $132.4 \mathrm{mg}(104.4 \mathrm{mg})$ for the PIB-H group, i.e., a mean difference between the $\mathrm{Cl}$ and PIB-H groups of $41 \mathrm{mg}$ ( $95 \% \mathrm{Cl}:-31.7$ to 113.7 ), $p=0.26$. On day two, mean (SD) OMEDD consumption was $116.1 \mathrm{mg}(108.9 \mathrm{mg})$ for the PIB-L group and $80.5 \mathrm{mg}(61.6 \mathrm{mg})$ for the PIB-H group, i.e., a mean difference between $\mathrm{Cl}$ and $\mathrm{PIB}-\mathrm{H}$ of $69.3 \mathrm{mg}$ (95\% Cl: 6.3 to 132.2), $p=0.03$. On day three, mean (SD) OMEDD consumption was $92.5 \mathrm{mg}(86.4 \mathrm{mg})$ for the PIB-L group and $63.9 \mathrm{mg}(53.4 \mathrm{mg})$ for the PIB-H group, i.e., a mean difference between $\mathrm{Cl}$ and PIB-H of $114 \mathrm{mg}$ (95\% Cl: 40.5 to 188), $p=0.003$. Subgroup analyses of analgesia outcomes of the $\mathrm{Cl}$ group compared to the PIB-L and PIB-H groups on each postoperative day is summarised in Table 4.

\section{Multivariate Analysis}

We corrected for the covariates of age, gender, procedure type, use of ketamine infusion, type of opioid, and total 24 hourly ropivacaine dose per kilogram in our multivariate linear regression analysis. Age was 
the only statistically significant covariate affecting OMEDD use in the first two post-operative days: day one $(-0.59, p<0.0005)$, day two $(-0.5, p<0.0005)$, and day three $(-0.31, p=0.04)$.

\section{Adverse Events}

There was no significant difference in post-operative length of hospital stay, $p=0.64$. The mean (SD) length of stay for the $\mathrm{Cl}$ group and PIB group was 7.8 days (6.7) and 8.5 days (7.3) respectively.

There were three MET calls and one code blue noted in this patient population throughout the study period. One code blue was called for a patient in the Cl group, which was secondary to a vasovagal episode with complete resolution. Two patients in the PIB group had MET calls for type II respiratory failure in the setting of severe underlying pulmonary disease (chronic obstructive pulmonary disease, and granulomatosis with polyangiitis, respectively), both of which resulted in unplanned admissions to the intensive care unit. A third patient in the PIB group required a MET call for supraventricular tachycardia which resolved with intervention on the ward. Outside of MET calls and code blues, there was only one additional adverse event with a patient in the $\mathrm{Cl}$ group experiencing peri-oral numbness and tingling. The LA infusion was immediately ceased and symptoms subsequently resolved.

\section{Discussion}

A single-centre observational study was performed evaluating post-operative OMEDD consumption and NRS pain scores in patients receiving LA via extrapleural paravertebral catheters after thoracic surgery, comparing the delivery of LA via PIB with background continuous infusion (PIB group) to continuous infusion alone ( $\mathrm{Cl}$ group). Contrary to our hypothesis, in comparing the two groups, we observed no significant difference in OMEDD consumption on post-operative day one, and no significant difference in NRS pain scores on each post-operative day.

There was, however, a significant reduction in opiate consumption on post-operative day three in the PIB group compared to the $\mathrm{Cl}$ group. We also demonstrated that high dose PIB significantly reduced opiate consumption on post-operative days two and three. Moreover, there was a significant reduction in the use of LA rescue boluses on post-operative day three, as well as ketamine use as a rescue analgesic on postoperative days two and three.

Although we did not demonstrate a statistical reduction in OMEDD use on day one, our primary endpoint, there was a trend towards lower use of opiates with a $25.5 \%$ reduction in OMEDDs in the PIB group. We also showed a non-significant reduction in ketamine use on day one in the PIB group with $38.6 \%$ fewer patients requiring ketamine. We hypothesised that the use of ketamine may have been a confounder which reduced the significance of the OMEDD use, particularly on day one. However, our multivariate model was unable to demonstrate this, with patient age being the only covariate with a statistically significant effect on OMEDD use. It is interesting to note that there was no difference in pain scores, despite the differences in OMEDD consumption and use of IV ketamine. This may imply that our PIB 
patients used less opioid to reach the same level of comfort as their continuous infusion counterparts, and therefore, that the use of PIB has an opioid-sparing effect.

Comparison of continuous infusion and PIB as methods of LA delivery via extrapleural paravertebral catheters has been previously investigated with conflicting results. Fibla et al. (2015) [21] conducted a prospective randomised controlled trial of 80 patients who underwent thoracotomy, comparing continuous infusions of LA via paravertebral catheters to a PIB regimen. No statistically significant differences were observed in pain scores or analgesia requirements between the groups. However, while the total dose was the same, the concentration of the levobupivacaine differed and therefore the volume as well, with the PIB group getting a smaller volume of a higher concentration solution. Our results may differ from these findings for two reasons. Firstly, many studies have previously documented that volume may be more important than concentration [17-20,36]. Secondly, our patients received boluses more frequently than six-hourly, leading to more frequent delivery of LA into the extrapleural paravertebral space. Català et al. (1996) [22] conducted a prospective randomised study of 30 post-thoracotomy patients and found that intermittent bolusing was inferior compared to continuous infusion based on pain scores at rest and on movement. The small numbers in this trial, the relatively low dose of local anaesthetic, and the long duration of six hours between boluses may have affected the outcome.

The use of PIB has also been previously investigated in other peripheral nerve catheters with varying results, including adductor canal blocks $[18,23,24]$, femoral nerve blocks $[17,25]$, popliteal nerve blocks $[19,20]$, interscalene blocks [26,36], infraclavicular blocks [27] and transverse abdominal plane blocks [28]. Of these, five showed an improvement with the use of PIB when compared with continuous infusion, while six showed no difference and none showed inferiority. Importantly, the protocols employed by these studies varied, and it appears that frequency of bolusing may make a significant difference. A recent review article of the various aspects continuous peripheral nerve blocks by IIfeld (2017) [37] supports further research into the use of PIB including optimal delivery regimens as a method of delivering LA into peripheral nerve catheters.

There are several strengths and limitations of this study. This study is limited because it is a small, singlecentre, observational, non-randomised, retrospective study of a population with some heterogeneity, limiting the external validity of our findings. However, our hospital has all the typical characteristics of many tertiary institutions' thoracic units, and the surgical and anaesthesia perioperative protocols adopted by our centre are aligned with those in many other tertiary centres. Data collection was sometimes limited by incomplete or unclear documentation in the medical record. Furthermore, data collection was reliant upon routine nursing observations which were not strictly regulated in terms of timing and frequency. Nonetheless, we looked for many of these sources of bias and found that the two groups were comparable.

The use of multivariate linear regression modelling assists in quantifying the effect of confounding variables on the outcomes of interest, however the smaller sample size may still incur type two errors on analysed covariates, and belies splitting of the sample to test the model fit for efficacy. Under these 
circumstances, the statistical significance of the multivariate modelling must be interpreted with much caution.

As PIB was introduced to our institution in 2016, many of those in the continuous infusion group predated this, while all of those in the PIB group were after. Therefore, there is a potential for lead-time bias. However, as the study was conducted over a relatively short period of 14 months we expect this bias to be minimal. The small numbers also mean that it is not powered to analyse some clinical outcomes, such as post-operative length of stay or adverse effects.

Unlike other studies, the patients in our PIB group received a continuous background infusion as well as boluses. In fact, an average of only $18 \%$ of the ropivacaine was administered via boluses. Given that we were able to show that a higher percentage of boluses is more favourable, it is apparent that the relatively low PIB percentage has diluted the effects of the PIB, potentially leading to a type two error.

Nonetheless, if validated with a prospective randomised controlled trial, these findings have the potential to alter routine post-operative pain management after thoracic surgery for the better. Improvements in post-operative pain management could lead to enhanced recovery, reduced complications, and decreased length of hospital stay, therefore having positive impacts for patients in terms of morbidity, and hospitals in terms of cost and bed availability. Furthermore, this could precipitate further investigation of PIB regimens in other peripheral LA catheters.

In patients receiving extrapleural paravertebral catheters after thoracic surgery, the delivery of LA via PIB with background continuous infusion, compared to continuous infusion alone, was associated with reduction in OMEDD consumption, most significantly on day three post-operatively. There was also a concomitant reduction in ketamine use and the administration of LA rescue boluses, and no difference in pain scores or total daily ropivacaine dose. This effect was dose dependant, being more evident in the PIB-H group.

\section{Conclusion}

This study has demonstrated that PIB via an extrapleural paravertebral catheter may provide superior analgesia, but a prospective randomised controlled trial is required. This study provides us with important information regarding prospective endpoints and will provide necessary data for the appropriate powering of such a trial.

\section{Declarations}

Ethics approval and consent to participate: This study was submitted to and approved by the Austin Health Ethics Committee - LNR/17/Austin/466

Consent for publication: Not applicable. 
Availability of data and material: The dataset used and analysed during the current study are available from the corresponding author on reasonable request.

Competing interests: No external funding and no competing interests declared.

Funding: Not applicable

\section{Authors' contribution:}

All authors have read and approved the manuscript.

BB made substantial contributions to acquisition, analysis and interpretation of data. BB was also involved in drafting the manuscript.

LuW made substantial contributions to acquisition, analysis and interpretation of data. LuW was also involved in drafting the manuscript.

MK made substantial contributions to acquisition, analysis and interpretation of data. MK was also involved in drafting the manuscript.

CT made substantial contribution to analysis and interpretation of data. CT was also involved in drafting the manuscript.

LaW made substantial contribution to the interpretation of data and was involved in revising the manuscript for intellectual content.

BP made substantial contributions to conception and design as well as drafting and appraising the manuscript.

Acknowledgments: Not applicable

\section{References}

1. Mesbah A, Yeung J, Gao F. Pain after thoracotomy. BJA Educ. 2016 Jan 1;16(1):1-7.

2. McKenna RJ, Houck W, Fuller CB. Video-assisted thoracic surgery lobectomy: experience with 1,100 cases. Ann Thorac Surg. 2006 Feb;81(2):421-5; discussion 425-426.

3. Kavanagh BP, Katz J, Sandler AN. Pain control after thoracic surgery. A review of current techniques. Anesthesiology. 1994 Sep;81(3):737-59.

4. Wildgaard K, Ravn J, Kehlet H. Chronic post-thoracotomy pain: a critical review of pathogenic mechanisms and strategies for prevention. Eur J Cardio-Thorac Surg Off J Eur Assoc Cardio-Thorac Surg. 2009 Jul;36(1):170-80. 
5. Grosen K, Laue Petersen G, Pfeiffer-Jensen M, Hoejsgaard A, Pilegaard HK. Persistent post-surgical pain following anterior thoracotomy for lung cancer: a cross-sectional study of prevalence, characteristics and interference with functioning. Eur J Cardio-Thorac Surg Off J Eur Assoc Cardio-Thorac Surg. 2013 Jan;43(1):95-103.

6. Cook E, Downs C. Analgesia After Thoracotomy - The Role of the Extrapleural Paravertebral Catheter. $2005 ; 15$.

7. Bilgin M, Akcali Y, Oguzkaya F. Extrapleural regional versus systemic analgesia for relieving postthoracotomy pain: a clinical study of bupivacaine compared with metamizol. J Thorac Cardiovasc Surg. 2003 Nov;126(5):1580-3.

8. Kaiser AM, Zollinger A, De Lorenzi D, Largiadèr F, Weder W. Prospective, randomized comparison of extrapleural versus epidural analgesia for postthoracotomy pain. Ann Thorac Surg. 1998 Aug;66(2):36772.

9. Sullivan E, Grannis FW, Ferrell B, Dunst M. Continuous extrapleural intercostal nerve block with continuous infusion of lidocaine after thoracotomy. A descriptive pilot study. Chest. 1995 Dec;108(6):1718-23.

10. Richardson J, Sabanathan S, Jones J, Shah RD, Cheema S, Mearns AJ. A prospective, randomized comparison of preoperative and continuous balanced epidural or paravertebral bupivacaine on postthoracotomy pain, pulmonary function and stress responses. Br J Anaesth. 1999 Sep;83(3):387-92.

11. Sabanathan S, Mearns AJ, Smith PJB, Eng J, Berrisford RG, Bibby SR, et al. Efficacy of continuous extrapleural intercostal nerve block on post-thoracotomy pain and pulmonary mechanics. Br J Surg. 2005 Dec 8;77(2):221-5.

12. Pintaric TS, Potocnik I, Hadzic A, Stupnik T, Pintaric M, Novak Jankovic V. Comparison of continuous thoracic epidural with paravertebral block on perioperative analgesia and hemodynamic stability in patients having open lung surgery. Reg Anesth Pain Med. 2011 Jun;36(3):256-60.

13. Kaynar AM, Shankar KB. Epidural Infusion: Continuous or Bolus? Anesth Analg. 1999 Aug;89(2):534.

14. Lim Y, Sia ATH, Ocampo C. Automated regular boluses for epidural analgesia: a comparison with continuous infusion. Int J Obstet Anesth. 2005 Oct;14(4):305-9.

15. Sia AT, Lim Y, Ocampo C. A comparison of a basal infusion with automated mandatory boluses in parturient-controlled epidural analgesia during labor. Anesth Analg. 2007 Mar;104(3):673-8.

16. Wong CA, Ratliff JT, Sullivan JT, Scavone BM, Toledo P, McCarthy RJ. A randomized comparison of programmed intermittent epidural bolus with continuous epidural infusion for labor analgesia. Anesth Analg. 2006 Mar;102(3):904-9. 
17. Hillegass MG, Field LC, Stewart SR, Borckardt JJ, Dong L, Kotlowski PE, et al. The efficacy of automated intermittent boluses for continuous femoral nerve block: a prospective, randomized comparison to continuous infusions. J Clin Anesth. 2013 Jun;25(4):281-8.

18. Thapa D, Ahuja V, Verma P, Gombar S, Gupta R, Dhiman D. Post-operative analgesia using intermittent vs. continuous adductor canal block technique: a randomized controlled trial. Acta Anaesthesiol Scand. 2016 Nov;60(10):1379-85.

19. Taboada M, Rodríguez J, Bermudez M, Valiño C, Ulloa B, Aneiros F, et al. A “new” automated bolus technique for continuous popliteal block: a prospective, randomized comparison with a continuous infusion technique. Anesth Analg. 2008 Oct;107(4):1433-7.

20. Taboada M, Rodríguez J, Bermudez M, Amor M, Ulloa B, Aneiros F, et al. Comparison of continuous infusion versus automated bolus for postoperative patient-controlled analgesia with popliteal sciatic nerve catheters. Anesthesiology. 2009 Jan;110(1):150-4.

21. Fibla JJ, Molins L, Mier JM, Hernandez J, Sierra A. A randomized prospective study of analgesic quality after thoracotomy: paravertebral block with bolus versus continuous infusion with an elastomeric pump. Eur J Cardio-Thorac Surg Off J Eur Assoc Cardio-Thorac Surg. 2015 Apr;47(4):631-5.

22. Català E, Casas JI, Unzueta MC, Diaz X, Aliaga L, Villar Landeira JM. Continuous infusion is superior to bolus doses with thoracic paravertebral blocks after thoracotomies. J Cardiothorac Vasc Anesth. 1996 Aug;10(5):586-8.

23. Monahan AM, Sztain JF, Khatibi B, Furnish TJ, Jæger P, Sessler DI, et al. Continuous Adductor Canal Blocks: Does Varying Local Anesthetic Delivery Method (Automatic Repeated Bolus Doses Versus Continuous Basal Infusion) Influence Cutaneous Analgesia and Quadriceps Femoris Strength? A Randomized, Double-Masked, Controlled, Split-Body Volunteer Study. Anesth Analg. 2016 May;122(5):1681-8.

24. Jaeger P, Baggesgaard J, Sørensen JK, Ilfeld BM, Gottschau B, Graungaard B, et al. Adductor Canal Block With Continuous Infusion Versus Intermittent Boluses and Morphine Consumption: A Randomized, Blinded, Controlled Clinical Trial. Anesth Analg. 2018 Jun;126(6):2069-77.

25. Charous MT, Madison SJ, Suresh PJ, Sandhu NS, Loland VJ, Mariano ER, et al. Continuous femoral nerve blocks: varying local anesthetic delivery method (bolus versus basal) to minimize quadriceps motor block while maintaining sensory block. Anesthesiology. 2011 Oct;115(4):774-81.

26. Hamdani M, Chassot O, Fournier R. Ultrasound-guided continuous interscalene block: the influence of local anesthetic background delivery method on postoperative analgesia after shoulder surgery: a randomized trial. Reg Anesth Pain Med. 2014 Oct;39(5):387-93. 
27. Ilfeld BM, Morey TE, Enneking FK. Infraclavicular perineural local anesthetic infusion: a comparison of three dosing regimens for postoperative analgesia. Anesthesiology. 2004 Feb;100(2):395-402.

28. Khatibi B, Said ET, Sztain JF, Monahan AM, Gabriel RA, Furnish TJ, et al. Continuous Transversus Abdominis Plane Nerve Blocks: Does Varying Local Anesthetic Delivery Method-Automatic Repeated Bolus Versus Continuous Basal Infusion-Influence the Extent of Sensation to Cold?: A Randomized, TripleMasked, Crossover Study in Volunteers. Anesth Analg. 2017;124(4):1298-303.

29. Kim SS. Intrathoracic extrapleural lesions: MDCT [Internet]. 2010 [cited 2018 May 24]. Available from: https://posterng.netkey.at/esr/viewing/index.php? module=viewing_poster\&task=viewsection\&pi=100991\&ti=305058\&searchkey=

30. Knotkova H, Fine PG, Portenoy RK. Opioid rotation: the science and the limitations of the equianalgesic dose table. J Pain Symptom Manage. 2009 Sep;38(3):426-39.

31. Pereira J, Lawlor P, Vigano A, Dorgan M, Bruera E. Equianalgesic dose ratios for opioids. a critical review and proposals for long-term dosing. J Pain Symptom Manage. 2001 Aug;22(2):672-87.

32. Mercadante S, Caraceni A. Conversion ratios for opioid switching in the treatment of cancer pain: a systematic review. Palliat Med. 2011 Jul;25(5):504-15.

33. Professional documents - Faculty of pain medicine [Internet]. [cited 2018 Aug 2]. Available from: http://fpm.anzca.edu.au/resources/professional-documents

34. Downie WW, Leatham PA, Rhind VM, Wright V, Branco JA, Anderson JA. Studies with pain rating scales. Ann Rheum Dis. 1978 Aug;37(4):378-81.

35. Naropin (ropivicaine) dosing, indications, interactions, adverse effects, and more [Internet]. [cited 2018 May 25]. Available from: https://reference.medscape.com/drug/naropin-ropivacaine-343367

36. Byeon GJ, Shin SW, Yoon JU, Kim EJ, Baek SH, Ri HS. Infusion Methods for Continuous Interscalene Brachial Plexus Block for Postoperative Pain Control after Arthroscopic Rotator Cuff Repair. Korean J Pain. 2015 Jul;28(3):210-6.

37. Ilfeld BM. Continuous Peripheral Nerve Blocks: An Update of the Published Evidence and Comparison With Novel, Alternative Analgesic Modalities. Anesth Analg. 2017;124(1):308-35.

\section{Tables}


Table 1: Number of patients in each group on each post-operative day (POD)

\begin{tabular}{|l|l|l|l|l|l|}
\hline & \multirow{2}{*}{ CI group (n, \%) } & \multicolumn{2}{|l|}{ PIB group } & \multirow{2}{*}{ Total (n) } \\
\cline { 3 - 5 } & & PIB-L (n, \%) & PIB-H (n, \%) & PIB total (n) & \\
\hline POD 1 & $29(34.5 \%)$ & $34(40.5 \%)$ & $21(25.0 \%)$ & $55(65.5 \%)$ & 84 \\
\hline POD 2 & $23(29.5 \%)$ & $34(43.6 \%)$ & $21(26.9 \%)$ & $55(70.5 \%)$ & 78 \\
\hline POD 3 & $15(24.6 \%)$ & $26(42.6 \%)$ & $20(32.8 \%)$ & $46(75.4 \%)$ & 61 \\
\hline
\end{tabular}

The percentage is calculated as a proportion of the total number of patients.

POD: post-operative day

$\mathrm{n}=$ number

CI: continuous infusion; less than $10 \%$ of the total daily ropivacaine dose delivered as a bolus

PIB: programmed intermittent bolus; more than $10 \%$ of the total daily ropivacaine dose delivered as a bolus

PIB-L: low dose programmed intermittent bolus; $10-25 \%$ of the total daily ropivacaine dose delivered as a bolus

PIB-H: high; dose programmed intermittent bolus; more than $25 \%$ of the total daily ropivacaine dose delivered as a bolus

Table 2: Demographics and clinical information of the continuous infusion (CI) group and the programmed intermittent bolus (PIB) group 


\begin{tabular}{|c|c|c|c|}
\hline & CI group & PIB group & p-value \\
\hline \multicolumn{4}{|l|}{ Demographics on post-operative day 1} \\
\hline Age: mean years (SD) & $55.3(18.0)$ & $60.6(13.3)$ & 0.13 \\
\hline Sex: number (\%) male & $14(48.3 \%)$ & $26(47.3 \%)$ & 1.00 \\
\hline BMI: mean $\mathrm{kg} / \mathrm{m}^{2}(\mathrm{SD})$ & $27.4(5.0)$ & $26.6(5.3)$ & 0.55 \\
\hline Pre-operative OMEDD: median mg (IQR) & $0(0-0)$ & $0(0-0)$ & 1.00 \\
\hline \multicolumn{4}{|l|}{ Type of surgery: number of patients (\%) } \\
\hline VATS & $14(48.3 \%)$ & $27(49.1 \%)$ & 1.00 \\
\hline Thoracotomy & $15(51.7 \%)$ & $28(50.9 \%)$ & 1.00 \\
\hline \multicolumn{4}{|c|}{ Primary opiate on post-operative day 1: number of patients (\%) } \\
\hline Fentanyl IV & $9(31.0 \%)$ & $19(34.5 \%)$ & 0.75 \\
\hline Morphine IV & $12(41.4 \%)$ & $12(21.8 \%)$ & 0.19 \\
\hline Oxycodone IV & $4(13.8 \%)$ & $9(16.4 \%)$ & 0.76 \\
\hline Oxycodone PO & $4(13.8 \%)$ & $14(25.5 \%)$ & 0.09 \\
\hline \multicolumn{4}{|c|}{ Total daily dose of ropivacaine: mean mg (SD) } \\
\hline POD 1 & $497(111)$ & $484(116)$ & 0.61 \\
\hline POD 2 & $505(102)$ & $501(113)$ & 0.87 \\
\hline POD 3 & $553(70)$ & $503(133)$ & 0.17 \\
\hline \multicolumn{4}{|c|}{ Percentage of ropivacaine delivered as a bolus: median (IQR) } \\
\hline POD 1 & $0(0-0)$ & $17.2(13.5-38.5)$ & $<0.0001$ \\
\hline POD 2 & $0(0-0)$ & $17.2(13.5-38.5)$ & $<0.0001$ \\
\hline POD 3 & $0(0-4.7)$ & $20.0(13.5-38.5)$ & 0.0001 \\
\hline
\end{tabular}

CI: continuous infusion; less than $10 \%$ of the total daily ropivacaine dose delivered as a bolus PIB: programmed intermittent bolus; more than $10 \%$ of the total daily ropivacaine dose delivered as a bolus

SD: standard deviation 
BMI: body mass index

POD: post-operative day

IQR: interquartile range

Table 3: Post-operative analgesia outcomes of the continuous infusion (CI) group and the programmed intermittent bolus (PIB) group on each post-operative day (POD)

\begin{tabular}{|l|l|l|l|}
\hline & CI group & PIB group & p-value \\
\hline OMEDD consumption: mean mg (SD) \\
\hline POD 1 & $173.4(139.8)$ & $129.2(100.4)$ & 0.10 \\
\hline POD 2 & $149.8(130.2)$ & $102.5(94.6)$ & 0.08 \\
\hline POD 3 & $178.1(150.6)$ & $80.1(74.6)$ & 0.001 \\
\hline Maximum pain score: mean score (SD) \\
\hline POD 1 & $6.8(1.9)$ & $6.3(2.3)$ & 0.31 \\
\hline POD 2 & $6.3(1.8)$ & $5.4(2.1)$ & 0.11 \\
\hline POD 3 & $6.2(2.7)$ & $5.4(2.3)$ & 0.25 \\
\hline Ketamine use: number of patients (\%) \\
\hline POD 1 & $6(20.7 \%)$ & $7(12.7 \%)$ & 0.36 \\
\hline POD 2 & $6(26.1 \%)$ & $3(5.5 \%)$ & 0.02 \\
\hline POD 3 & $3(20.0 \%)$ & $1(1.8 \%)$ & 0.04 \\
\hline Number of patients requiring rescue boluses (\%) \\
\hline POD 1 & $4(13.8 \%)$ & $2(3.6 \%)$ & 0.42 \\
\hline POD 2 & $2(8.7 \%)$ & $0(0.0 \%)$ & 0.08 \\
\hline POD 3 & $4(26.7 \%)$ & $1(1.8 \%)$ & 0.01 \\
\hline
\end{tabular}

CI: continuous infusion; less than $10 \%$ of the total daily ropivacaine dose delivered as a bolus

PIB: programmed intermittent bolus; more than $10 \%$ of the total daily ropivacaine dose delivered as a bolus

OMEDD: oral morphine equivalent daily dose 
POD: post-operative day

SD: standard deviation

Table 4: Subgroup analyses of analgesia outcomes of the continuous infusion (CI) group compared to the low dose programmed intermittent bolus (PIB-L) and high dose programmed intermittent bolus (PIB-H) groups on each post-operative day (POD)

\begin{tabular}{|c|c|c|c|c|}
\hline & CI group & PIB-L group & PIB-H group & $\begin{array}{l}\text { p-value } \\
\text { (CI vs PIB-H) }\end{array}$ \\
\hline \multicolumn{5}{|c|}{ OMEDD consumption: mean mg (SD) } \\
\hline POD 1 & $173.4(139.8)$ & $127.3(99.4)$ & $132.4(104.4)$ & 0.19 \\
\hline POD 2 & $149.8(130.2)$ & $116.1(108.9)$ & $80.5(61.6)$ & 0.03 \\
\hline POD 3 & $178.1(150.6)$ & $92.5(84.7)$ & $63.9(45.2)$ & 0.003 \\
\hline \multicolumn{5}{|c|}{ Maximum pain score: mean score (SD) } \\
\hline POD 1 & $6.8(1.9)$ & $6.6(2.2)$ & $5.8(2.4)$ & 0.10 \\
\hline POD 2 & $6.3(1.8)$ & $5.6(2.1)$ & $5.2(2.2)$ & 0.07 \\
\hline POD 3 & $6.2(2.7)$ & $5.2(2.2)$ & $4.6(2.6)$ & 0.08 \\
\hline \multicolumn{5}{|c|}{ Ketamine use: number of patients (\%) } \\
\hline POD 1 & $6(20.7 \%)$ & $4(11.8 \%)$ & $3(14.3 \%)$ & 0.72 \\
\hline POD 2 & $6(26.1 \%)$ & $2(5.9 \%)$ & $1(4.8 \%)$ & 0.10 \\
\hline POD 3 & $3(20.0 \%)$ & $0(0.0 \%)$ & $2(10.0 \%)$ & 0.63 \\
\hline \multicolumn{5}{|c|}{ Number of patients requiring rescue boluses (\%) } \\
\hline POD 1 & $4(13.8 \%)$ & $1(2.9 \%)$ & $1(4.8 \%)$ & 0.38 \\
\hline POD 2 & $2(8.7 \%)$ & $0(0.0 \%)$ & $0(0.0 \%)$ & 0.49 \\
\hline POD 3 & $4(26.7 \%)$ & $0(0.0 \%)$ & $1(5.0 \%)$ & 0.14 \\
\hline
\end{tabular}

CI: continuous infusion; less than $10 \%$ of the total daily ropivacaine dose delivered as a bolus 
PIB: programmed intermittent bolus; more than $10 \%$ of the total daily ropivacaine dose delivered as a bolus

PIB-L: low dose programmed intermittent bolus; $10-25 \%$ of the total daily ropivacaine dose delivered as a bolus

PIB-H: high; dose programmed intermittent bolus; more than $25 \%$ of the total daily ropivacaine dose delivered as a bolus

OMEDD: oral morphine equivalent daily dose

POD: post-operative day

SD: standard deviation

\section{Figures}




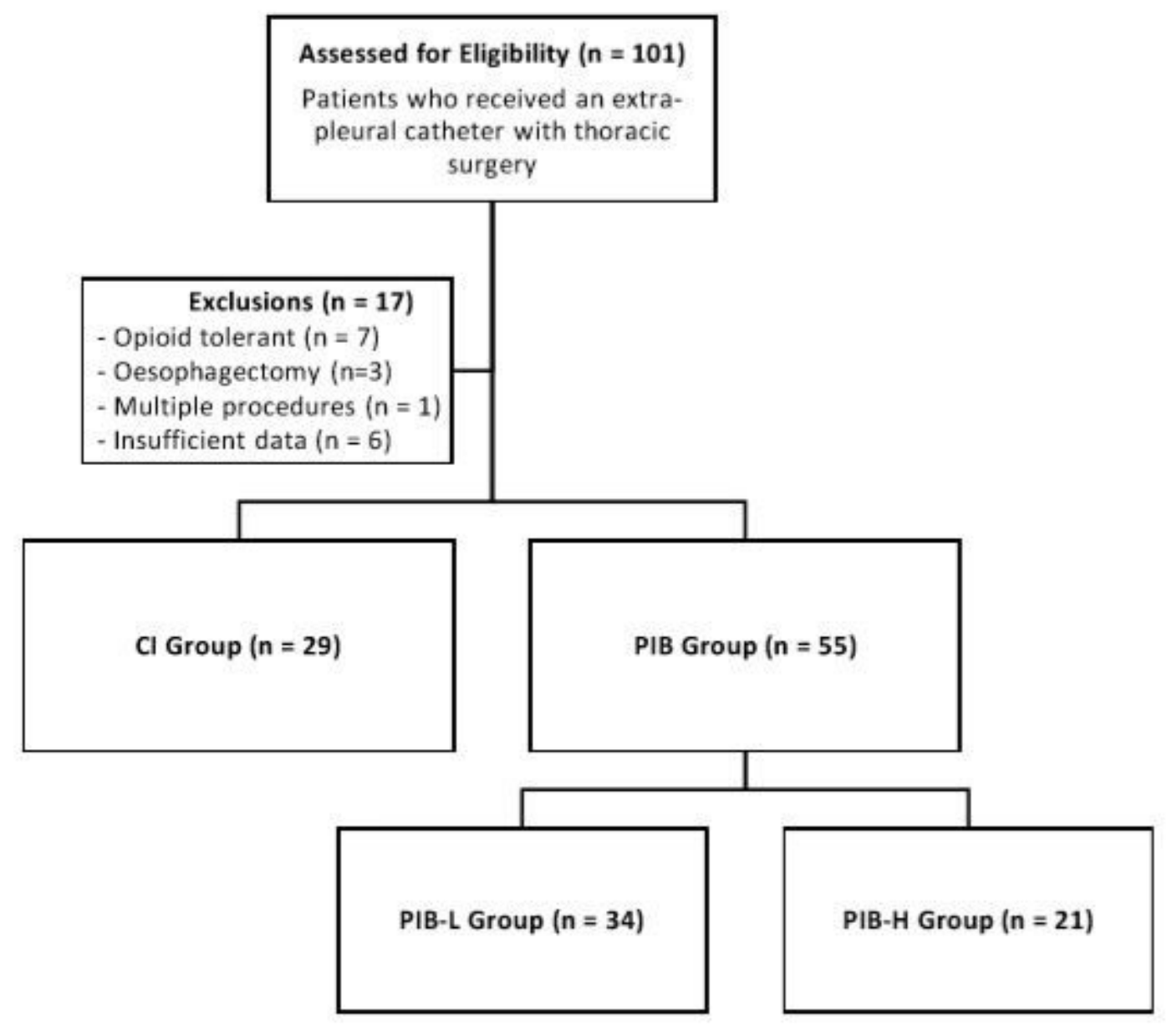

Figure 1

Flow chart of patient assessment, inclusions, and exclusions Figure 1 Legend: POD: post-operative day $n$ $=$ number $\mathrm{Cl}$ : continuous infusion; less than $10 \%$ of the total daily ropivacaine dose delivered as a bolus PIB: programmed intermittent bolus; more than $10 \%$ of the total daily ropivacaine dose delivered as a bolus PIB-L: low dose programmed intermittent bolus; $10-25 \%$ of the total daily ropivacaine dose delivered as a bolus PIB-H: high; dose programmed intermittent bolus; more than $25 \%$ of the total daily ropivacaine dose delivered as a bolus 
250

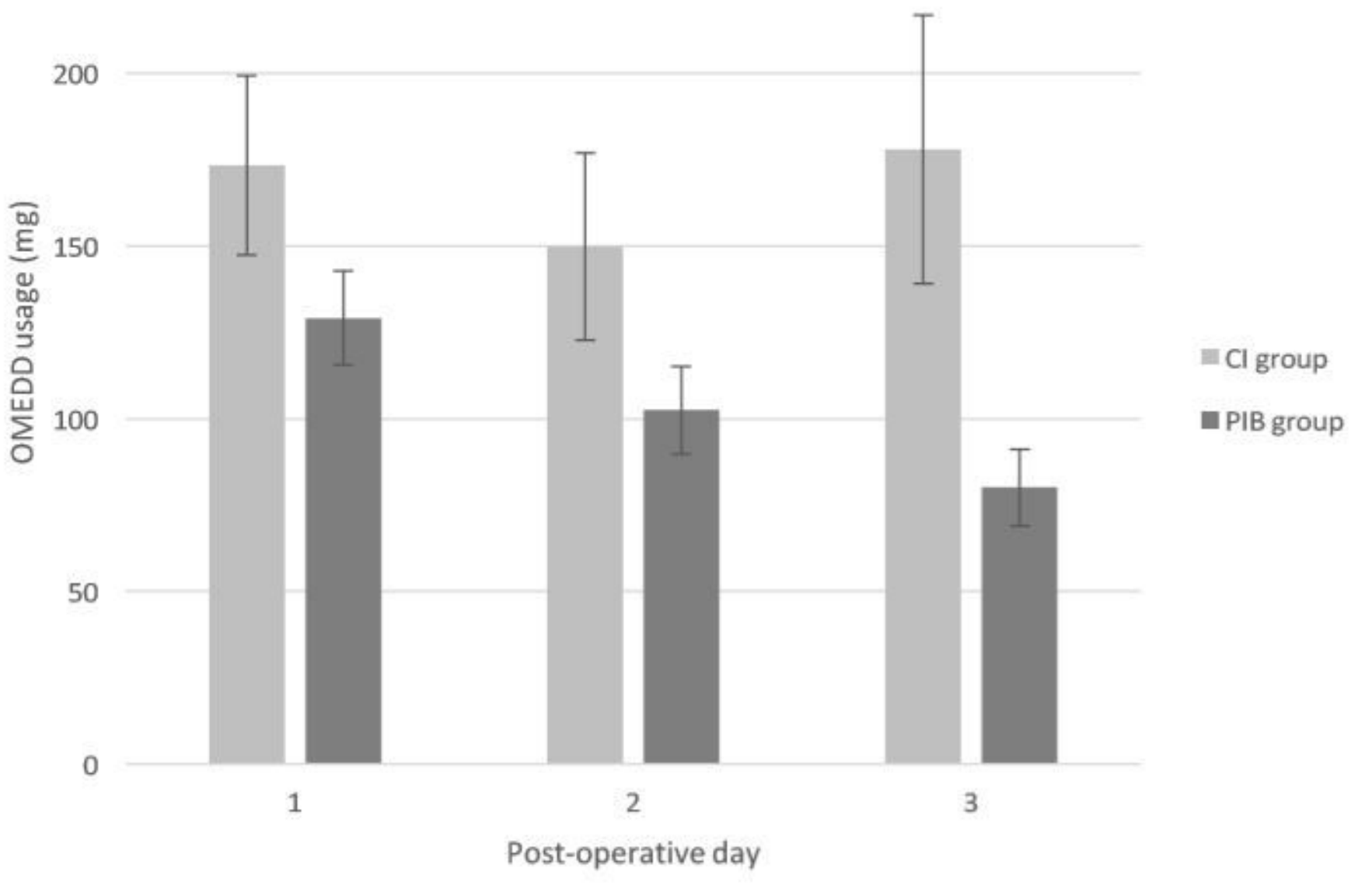

Figure 2

A comparison of the mean post-operative OMEDD consumption between the continuous infusion (CI) group and the programmed intermittent bolus (PIB) group on each post-operative day (POD) Figure 2 Legend: $\mathrm{Cl}$ : continuous infusion; less than $10 \%$ of the total daily ropivacaine dose delivered as a bolus PIB: programmed intermittent bolus; more than $10 \%$ of the total daily ropivacaine dose delivered as a bolus OMEDD: oral morphine equivalent daily dose mg: milligrams POD: post-operative day Error bars are mean \pm standard error of the mean (SEM). There was a significant difference between groups on POD 3 . 


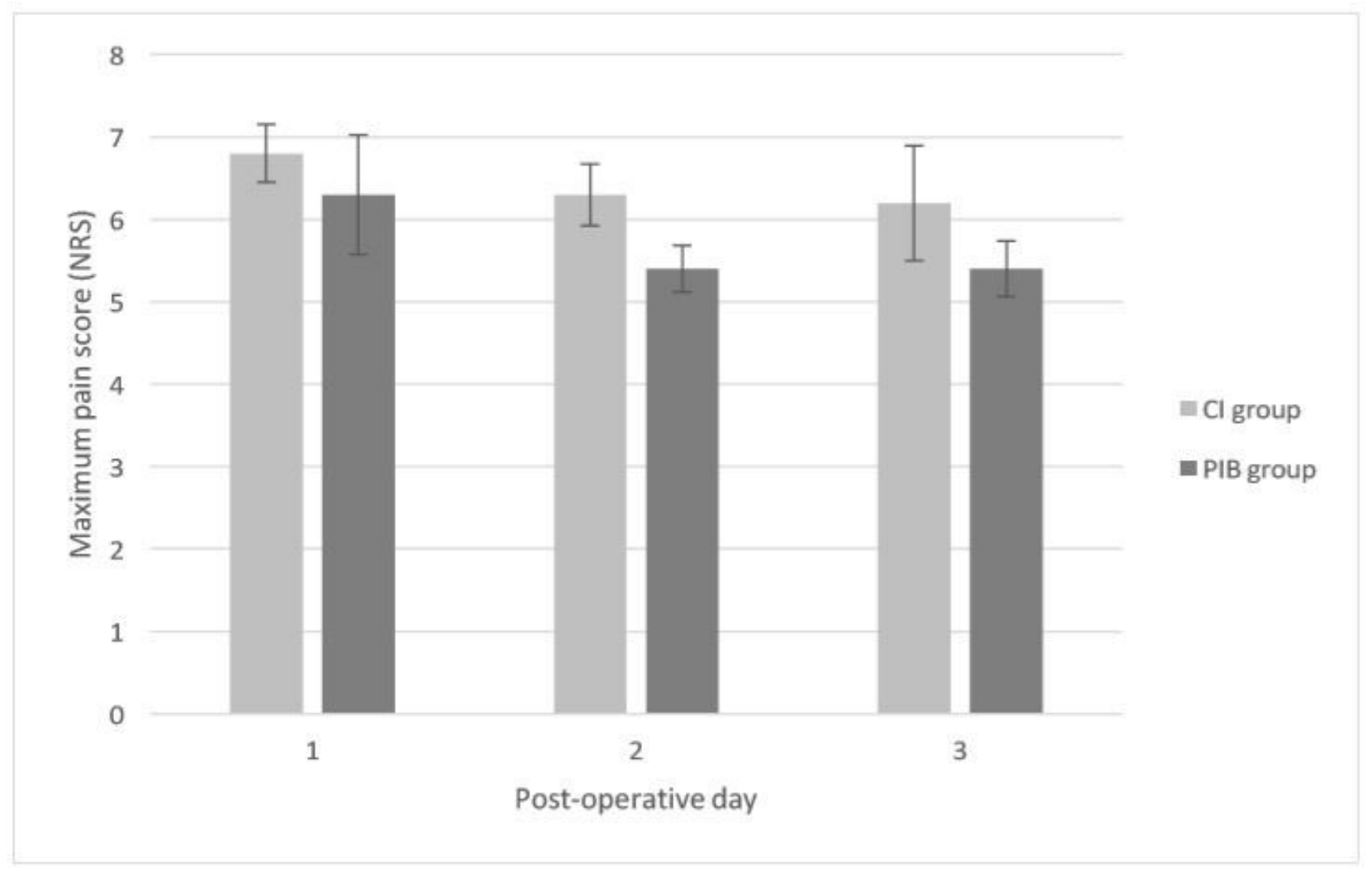

\section{Figure 3}

A comparison of mean post-operative numerical rating scale (NRS) pain scores between the continuous infusion ( $\mathrm{Cl}$ ) group and the programmed intermittent bolus (PIB) group on each post-operative day (POD) Figure 3 Legend: Cl: continuous infusion; less than $10 \%$ of the total daily ropivacaine dose delivered as a bolus. PIB: programmed intermittent bolus; more than $10 \%$ of the total daily ropivacaine dose delivered as a bolus NRS: numerical rating scale; patients are asked to provide a verbal rating on the severity of their pain from zero to ten, where zero is no pain and ten is the worst possible pain Error bars are mean \pm standard error of the mean (SEM). There were no significant differences between groups. 